\title{
O IMPOSTO SOBRE A TRANSMISSÃO DE BENS IMÓVEIS (ITBI): PRINCIPAIS QUESTÕES
}

José Mauricio Conti

SUMÁRIO: 1. Evolução histórica do ITBI na Constituição. 2. Panorama legal. 3. Aspectos constitutivos da hipótese de incidência do ITBI. 3.1. Aspecto Material da Hipótese de Incidência. 3.2. Aspecto temporal da Hipótese de Incidência. 3.3. Aspecto Espacial da Hipótese de Incidência. 3.4. Aspecto pessoal da Hipótese de Incidência. 4. Conclusão. 5. Bibliografia.

SUMMARY: 1. Historical evolution of ITBI in the Constitution. 2. Legal panorama. 3. Constituent aspects of the hypothesis of incidence of ITBI. 3. 1. Material aspect of the Hypothesis of Incidence. 3. 2. Temporary aspect of the Hypothesis of Incidence. 3. 3. Space aspect of the Hypothesis of Incidence. 3. 4. Personal aspect of the Hypothesis of Incidence. 4. Condusion. 5. Bibliography.

SUMARIO: 1. Evolución histórica Del ITBI en la Constitución. 2. Panorama Legal. 3. Aspectos constitutivos de la hipótesis de la incidencia del ITB. 3.1. Aspecto Material de la hipótesis de la incidencia. 3.2. Aspecto temporal de la hipótesis de incidencia. 3.3. Aspecto espacial de la hipótesis de la incidencia. 3.4. Aspecto pessoal de la hipótesis de la incidencia. 4. Conclusión. 5. Bibliografia.

RESUMO: Neste artigo são analisadas as principais questões pertinentes ao Imposto sobre a Transmissão de Bens Imóveis (ITBI). Começando com a evolução histórica é fornecida uma visão geral sobre os principais aspectos relacionados ao tributo municipal. A seguir, os argumentos polêmicos sobre a conveniência da progressividade e da proporcionalidade são apresentados, e na conclusão sintetiza-se as idéias essenciais do tema.

Doutor e Mestre em Direito Econômico Financeiro pela Universidade de São Paulo USP. Protessor Assistente-Doutor da Faculdade de Direito da Universidade de São Paulo. Juiz de Direito em Săo Paulo. 
ABSTRACT: In this article there are analyzed the main pertinent subjects to the Tax on the Transmission of Immobile Goods (ITBI). Beginning with the historical evolution a general vision is supplied on the main aspects related to the municipal tribute. To proceed, the polemic arguments on the convenience of the progressivity and of the proportionality they are presented, and in the conclusion it is synthesized the essential ideas of the theme.

RESUMEN: En este artículo son analizados los principales temas pertinentes al impuesto sobre la transmisión de las mercancías inmóviles (ITBI). El comenzar con la evolución histórica una visión general se provee en los aspectos principales relacionados con el tributo municipal. En siguiente, son abordadas las discusiones polémicas en la conveniencia de la progresividad y de la proporcionalidad, y en la conclusión se sintetiza las ideas esenciales del tema.

PALAVRAS-CHAVE: Direito Tributário Brasileiro. Imposto. Bens Imóveis. Proporcionalidade. Progressividade.

KEY-WORDS: Brazilian Tributary Law. Tax. Immobile Goods. Proportionality. Progressivity.

PALABRAS-LLAVES: Derecho Tributario Brasileño. Impuesto. Mercancías Inmóviles, Proporcionalidad. Progresividad.

\section{Evolução histórica do ITBI na Constituição}

O TTBI surgiu no Direito brasileiro em 1809 , por meio do Alvará 3, de junho do referido ano, com a denominação de imposto da sisa (pela qual este tributo é vulgarmente conhecido até os dias atuais), tendo a primeira previsão constitucional surgido na Carta de 1891, que estabelecia, em seu art. 9a imposto sobre transmissão de propriedade.

A Constituição de 1934 estabeleceu uma divisão, criando dois impostos, ambos de competência dos Estados: o imposto de transmissão de 
propriedade causa mortis (art. 8a $, \mathrm{I}, \mathrm{b}$ ) e o imposto sobre a transmissão de propriedade imobiliária inter vivos (art. $8^{\mathrm{a}}, \mathrm{I}, \mathrm{c}$ ). O mesmo texto foi mantido pela Constituição de 1937 (art. 23, I, be c). Também não houve alteração por ocasião da Constituição de 1946 , sendo mantidos ambos os impostos tal como já estavam previstos (art. 19, II e III).

A Emenda Constitucional $\mathrm{n}^{\mathrm{a}} 5$, de 1961 , passa para a competência dos Municípios o imposto de transmissão de bens inter vivos (art. 29, III), mantendo o imposto causa mortis, com pequenas alterações na redação (art. 19, I, e $\S 1^{\circ}$ e $2^{\circ}$ ).

A Emenda Constitucional 18, de 1965, restabelece a união dos impostos de transmissão de bens imóveis, inter vivos e causa mortis, mantendo-os na competência dos Estados, com algumas novidades em termos de hipóteses de incidência (art. 9⿱乛龰, caput, e $\S \S 1^{\circ}$ a $4^{\circ}$ ). Pouca modificação houve por ocasião da Constituição de 1967 (art. 24, I, e $\$ 2^{\circ}$ ). O mesmo se observa com a edição do Ato Complementar 40, de 1968, que produz pequena alteração no texto do $\S 2^{\circ}$, mantendo, no mais, a redação anterior. E a Emenda Constitucional 1, de 1969, mantém, em linhas gerais, o texto da Constituição de 1967 (art. 23, I e $\$ \S 2^{\circ}$ e $3^{\circ}$ ).

Finalmente, a Constituição de 1988 traz a redação hoje vigente, que atribui aos Estados e Distrito Federal a competência para a instituição do imposto de transmissão causa mortis (art. 155, I), e aos Municípios a competência para a instituição do imposto de transmissão de bens imóveis inter vivos (art. 156, II).

\section{Panorama legal}

Atualmente, o imposto de transmissão de bens imóveis inter vivos, que passarei a denominar simplesmente de ITBI, tem sua fonte na Constituição, no já mencionado art. 156, inciso II.

A Lei Complementar que trata do ITBI, nos termos em que exige o art. 146, III, a, da Constituição, é, por recepção, o Código Tributário Nacional (Lei 5.172, de 25.10.66), que regula este tributo em seus artigos 35 a 42 . Convém observar que o CTN foi editado sob a égide da Constituição de 1946 e suas emendas, época em que estava vigente o ITBI unificado com o Imposto de Transmissão Causa Mortis. Por esta razão, os arts. 35 a 42 tratam dos dois impostos simultaneamente, cabendo ao intérprete identificar os dispositivos que se referem a um e a outro imposto. 
Em termos de legislação ordinária., o ITBI, sendo da competência dos Municípios, tem legislação própria para cada um deles.

No município de São Paulo, a legislação básica é a Lei Municipal $\mathrm{n}^{\mathrm{a}} 11.154$, de 30 de dezembro de 1991 , regulada pelo Decreto $\mathrm{n}^{\mathbf{a}} 31.134$, de 24 de janeiro de 1992. Recentemente, pode-se destacar ainda o Decreto 37.344, de 20 de fevereiro de 1998, que consolida a legislação tributária do Município de São Paulo, referindo-se ao ITBI em seus artigos 69 a 95 .

\section{Aspectos constitutivos da hipótese de incidência do ITBI}

Analisaremos a seguir o ITBI sob a ótica dos diversos aspectos que compõem sua hipótese de incidência, quais sejam, os aspectos pessoal, material, temporal, espacial, pessoal e quantitativo, a fim de melhor compreender este tributo.

\subsection{Aspecto material da hipótese de incidência}

Como a própria denominação do imposto estabelece, sua hipótese de incidência, ou fato gerador in abstrato, é, genericamente, a transmissão, por ato oneroso, de bens imóveis, excluindo-se a sucessão (causa mortís). A legislação tributária do município de São Paulo prevê ter o ITBI os seguintes fatos geradores (LM 11.154/91, art. $1^{\circ}$ ):

a) as transmissões, inter vivos, a qualquer título, por ato oneroso, de bens imóveis, por natureza ou acessão física, e a de direitos reais sobre bens imóveis, exceto os de garantia e as servidões;

b) a cessão, por ato oneroso, dos direitos relativos à aquisição de bens imóveis.

Esclarece a citada legislação, para evitar controvérsias, que estão compreendidas nestas hipóteses a compra e venda, a dação em pagamento, a permuta, a arrematação, a adjudicação, o uso, o usufruto, e a enfiteuse. Também incide o imposto na cessão de direitos do arrematante ou adjudicatário, depois de assinado o auto de arrematação ou adjudicação, bem como na cessão de direitos decorrente de compromisso de compra e venda. $O$ fato gerador do imposto abrange ainda a cessão de direitos à sucessão e a cessão de benfeitorias e construçôes em terreno compromissado à venda. Várias são as hipóteses de imunidades e isenções previstas, que não serão objeto de análise neste estudo. 
Convém esclarecer que bem imóvel por natureza é o solo com sua superfície, os seus acessórios e adjacências naturais, compreendendo as árvores e frutos pendentes, o espaço aéreo e o subsolo (Código Civil, art. 43, I). Bem imóvel por acessão física é tudo quanto o homem incorporar permanentemente ao solo, como a semente lançada à terra, os edifícios e construções, de modo que não possa retirar sem destruição, modificação, fratura, ou dano (Código Civil, art. 43, II). A acessão pode dar-se ainda pela formação de ilhas, por aluvião, por avulsão ou por abandono de álveo (art. 536 do Código Civil). Os direitos reais de garantia a que se refere a exceção constitucional são o penhor, a anticrese e a hipoteca (arts. 755 e seguintes do Código Civil).

\subsubsection{Casos de interesse}

Relativamente ao aspecto material da hipótese de incidência do imposto, algumas questões merecem estudo mais aprofundado.

3.1.1.1. É o caso, por exemplo, da divisão de patrimônio na separação judicial. É evidente que, em sendo o patrimônio dividido na metade, para os casos de bens adquiridos após o matrimônio em regime de comunhão de bens, não incide o imposto, pois não houve a transmissão da propriedade, mas tão somente partilha de bens que já pertenciam aos cônjuges.

Porém, pode ocorrer de, nesta partilha, por conveniência dos envolvidos, um deles ficar com uma parte do patrimônio imobiliário que corresponda a mais da metade do que the caberia se a partilha fosse realizada pelas regras impostas pelo regime de bens. Neste caso, surge a questão de saber se o ITBI incide sobre a respectiva diferença, como se tivesse havido uma transferência da propriedade.

No caso do Município de São Paulo, a legislação foi absolutamente clara, não deixando margem a dúvida, consoante se verifica do inciso VI do art. 70 do Decreto 37.344/98 (e art. $2^{\circ}$ da LM 11.154/91): "Estão compreendidos na incidência do imposto o valor dos imóveis que, na divisão de patrimônio comum ou na partilha, forem atribuídos a um dos cônjuges separados ou divorciados, ao cônjuge supérstite ou a qualquer herdeiro, acima da respectiva meação ou quinhão".

E a jurisprudência não tem decidido de maneira diversa: "Nada impede o casal de, ao fazer a partilha, atribuir a maioria dos bens a um deles. A circunstância de existirem bens móveis compensando a diferença é válida entre as partes interessadas, para efeito de equivalência da partilha. Perante o Fisco, no entanto, são considerados apenas os bens imóveis, passíveis de tributação" (Agravo de Instrumento n. 252.041-1 - São Paulo - rel. Toledo Silva - $4^{\circ}$ C Civ - v.u. - j. 20.4.95). 
Convém destacar que, nesta hipótese, deve ser analisado a que título se deu o excesso de meação - se oneroso ou gratuito. Isto porque, em sendo a título oneroso, ou seja, o excedente foi compensado por outras transferências ocorridas quando da partilha, configura-se a hipótese de incidência do ITBI. Por outro lado, se o excesso se deu a título gratuito, está configurada a hipótese de incidência do imposto estadual previsto no art. 155, I, da Constituição. Assim já decidiram os Tribunais: "SEPARAÇ̃̃O CONSENSUAL - Partilha - Excesso de meação a título gratuito, atribuído a um dos conjuges, em razão de acordo - Doação configurada - Incidência do imposto de transmissão de bens imóveis, tributo estadual - Artigo 155, inciso I, da constituição da República, e Lei Estadual n. 9.591, de 1966, com as alteraçōes da Lei Estadual n. 3.199, de 1981" (TJSP - $1^{\circ} \mathrm{C}$ Civ-AI 171.5451 - rel. Renan Lotufo - j. 26.5.92, in JTJ 139/205).

3.1.1.2. Outro caso interessante é o do usucapião. Tendo em vista tratarse de modo originário de aquisição da propriedade, não há que se falar, na hipótese de se adquirir bem imóvel por usucapião, de transmissão de propriedade, não sendo, por conseguinte, fato gerador do ITBI. Neste sentido já tem se manifestado a jurisprudência: "No usucapiāo não há transmissão de bens, e sim aquisição originária, em correspondência com o direito que se perde. Indevido, portanto, o ITBI" (TJMG - AI 17.162 - 10 C. - rel. Des. Paulo Tinôco, in RJ 110/104). Ou ainda: "Sendo o usucapiăo modo originário de adquirir a propriedade, lícito não será exigir do adquirente, conforme vem orientando a jurisprudência, o imposto de transmissão de bens imóveis. As obrigações fiscais necessárias ao registro de imóveis, de que fala o artigo 945 do $C P C$, são de outra qualidade, como o imposto territorial ou predial municipal" (TJSC-AC 29.161-1ำ C - Rel. Des. Protásio Leal - j. 30.8.89, in RJ 135/78).

\subsection{Aspecto temporal da hipótese de incidência - o momento de ocorrência do fato imponível}

Esta é uma questão um tanto tormentosa com relação ao ITBI.

Em sendo um dos fatos geradores do imposto "as transmissões de bens imóveis", o momento de ocorrência do fato gerador, nestas hipóteses, é o da transmissão da propriedade do bem.

Pelas regras de Direito Civil vigentes, a propriedade imobiliária transmite-se com o respectivo registro no Cartório de Registro de Imóveis 
competente. Portanto, somente nesta oportunidade é que poderia ser exigido o tributo. Assim já decidiu o STI: "A propriedade imobiliária apenas se transfere com o registro do respectivo título (CC, art. 530). $\mathrm{O}$ registro imobiliário é o fato gerador do Imposto de Transmissão de Bens Imóveis. Assim, a pretensão de cobrar o ITBI antes do registro imobiliário contraria o Ordenamento Jurídico" (STJ - REsp 12.546-0 - RJ - 1 T - Rel. Min. Gomes de Barros - DJU 30.11.92, in RJ 184/87).

No entanto, não é o que vem sendo observado, sendo o imposto exigido por ocasião da lavratura da escritura pública definitiva referente à negociação. E, não obstante a decisão da E. Corte de Justiça retro mencionada, a análise cuidadosa da questão permite concluir ser esta a posição mais correta, como se pretende demonstrar a seguir.

Isto porque o registro da escritura, na hipótese, é um ato que compōe o conjunto de atos necessários à transmissão da propriedade dos bens imóveis, e tem relevância específica para fins de direito civil, no sentido de torná-lo público e oponivel erga omnes. Nada impede que a lei tributária, à semelhança do que ocorre em vários outros impostos, escolha um dos atos ligados à hipótese de incidência para considerar como sendo o do momento da ocorrência do fato tributável.

A interpretação da legislação vigente, quer seja realizada pelo método sistemático, literal ou histórico, leva à mesma conclusão. $\mathrm{O}$ trabalho realizado por Alcides Sampaio acerca do assunto é minucioso, e não deixa margem a dúvidas. Mostra o autor que, desde a sua criação, o imposto teve como fato gerador o negócio jurídico de compra e venda ou ato equivalente, sendo a lavratura da escritura mero ato destinado a tornar - negócio oponível a terceiros, sem influência tributária, fato que se mostrou presente no decorrer de toda a evolução histórica do tributo, não se justificando, assim, que se tenha entendimento diverso.

A interpretação literal e sistemática, no pensamento do autor, leva ao mesmo desfecho. $O$ disposto no art. 156, II, da Constituição, mostra que o texto faz referência à "transmissão inter vivos, a qualquer título, por ato oneroso, de bens imóveis...". E, considerando que o registro imobiliário só pode ser efetuado na forma da Lei $6.015 / 73$, ficaria inócua a expressão "a qualquer título" inserida na norma constitucional, só fazendo sentido se estiver "associada aos diversos atos jurídicos que originam transferencia de imóveis (contratos de compra e venda ou permuta, arremataçôes em hasta pública etc.)". Argumenta ainda que "a onerosidade da situação 
nela mencionada certamente não está associada ao pagamento que se faz pelo registro da escritura ao RGI, mas, sim, à contraprestação devida pelo adquirente do bem imóvel ao alienante". E finaliza o raciocínio: "Por último, o Direito leva em conta a realidade em que se situa, sendo notório que o registro no RGI será feito pelo adquirente se, ou quando, quiser. Ora, sendo o tributo, por definição, uma prestação compulsória (CTN - art. $3^{\circ}$ ) e se caracterizando a obrigação tributária por ser uma obrigação ex lege, exatamente pelo fato de a vontade do sujeito passivo não exercer qualquer influência sobre o vínculo que o prende ao sujeito ativo, é desarrazoado supor que o legislador constituinte elegesse esse momento para fazer incidir a regra de tributação. .)" (ITBI: momento..., p. 25).

No mesmo sentido está o pensamento de Edgar Neves da Silva: "Conclui-se que, em tendo o legislador municipal, na ausência de qualquer regramento de lei complementar, com fundamento na constitucional disposição do art. 146, - norma geral sobre matéria de legislação tributária - acolhido como aspecto temporal do imposto municipal sobre transmissão, o ato da lavratura do respectivo instrumento contratual, agiu legalmente, podendo, destarte, a partir deste ato exigir a satisfação do crédito tributário respectivo" (Aspecto temporal..., p. 100).

Cabe ressaltar, outrossim, que mera promessa, ou outro ato prévio àquele destinado à transmissão definitiva da propriedade, não caracteriza o fato gerador do imposto. Esta questão foi analisada com muita competencia e precisão pelo Tribunal de Justiça do Paraná, em decisão cujos principais trechos convém transcrever: "No sistema brasileiro, os contratos não bastam para transferir o domínio, sendo necessário, para completar o processo translativo, no caso de bens imóveis, a transcrição do título de transferência no respectivo Registro de Imóvel (art. 530, I, do CC). Diz o art. 533 do CC: 'Os atos sujeitos à transcrição (art. 531 e 532, II e III), não transferem o domínio, senão da data em que se transcreverem (art. 856,860, parágrafo único)'. Destarte, não tendo as escrituras sido assinadas, não ocorreu a transcrição, e conseqüentemente, não se transferiu a propriedade do imóvel, que é a hipótese de incidência do ITBI, nos termos do art. 35, II do CTN. (...) Em resumo e finalmente, se a compra e venda prometida não é realizada, deixando as partes de aderir à escritura pública - que resta sem assinatura e cancelada pelo tabelião -, é inexigivel o imposto de transmissão." (Ap. e ReexNec. 202544 - $1^{\circ}$ C. j. 2.3 .93 - rel. Des. Oto Luiz Sponholz, in RT 704/175). Fm sentido 
semelhante encontramos decisão do $1^{\circ}$ TAC SP: "Segundo estabelece o art. 530, inciso I, do Código Civil, adquire-se a propriedade imóvel pela transcrição do título de transferência no registro de imóveis. Tal não ocorreu na hipótese vertente, pois cuida-se de compromisso particular nem sequer registrado e aquele pressupõe escritura pública, a teor do art. 134, inciso II, do Código Civil, na qual deve constar, obrigatoriamente, a transcrição das certidões negativas das Fazendas Públicas Nacional, Estadual e Municipal, de quaisquer impostos a que estejam sujeitos (art. 1137, do mesmo Código)" (Ac un da $7^{\circ} \mathrm{C}$ do $1^{\circ} \mathrm{TAC}$ SP - AC 498.6172 - rel. Juiz Roberto Midolla - j. 11.10.94, in RJIOB 1/8636). Em sentido semelhante: RT 618/158.

3.3. Aspecto espacial da hipótese de incidência - o local da ocorrência do fato imponível

Sendo o imposto da competência dos municípios, o local da ocorrência do fato gerador é o do município onde se localiza o imóvel objeto de transmissão, ou ao qual está ligada a cessão de direitos. Diversamente do que ocorre com o IPTU e ITR, no ITBI não há distinção entre zona urbana e rural, valendo, pois, para todo e qualquer imóvel.

OCTN, que previa este tributo na forma anterior, fundido ao Imposto de Transmissão Causa Mortis, estabelece, em seu art. 41, que "o imposto compete ao Estado da situação do imóvel transmitido, ou sobre que versarem os direitos cedidos (...)". A legislação paulistana prevê que o ITBI "refere-se a atos e contratos relativos a imóveis situados no território deste Município" (LM 11.154/91, art. 1").

\subsection{Aspecto pessoal da hipótese de incidência}

\subsubsection{Sujeito ativo}

A competência tributária para a instituição do ITBI pertence aos Municípios, por força do disposto no art. 156, II, da Constituição vigente, que devem exercê-la nos limites fixados pelo respectivo texto legal e pelo que consta do Código Tributário Nacional, arts. 35 a 41, feitas as devidas adaptações em face da cisão entre o ITBI e o Imposto de Transmissão Causa Mortis, ambos previstos nos mesmos artigos citados. 


\subsubsection{Sujeito passivo}

O art. 42 do CTN delega à lei ordinária a definição do contribuinte do imposto.

No município de São Paulo, a Lei Municipal 11.154/91, em seu art. $6^{\circ}$, prevê como sendo contribuintes (sujeitos passivos diretos):

a) os adquirentes dos bens ou direitos transmitidos;

b) os cedentes, nas cessões de direitos decorrentes de compromissos de compra e venda.

Neste imposto cumpre ressaltar um caso específico a ele aplicado de sujeição passiva indireta, prevista no art. 135 , VI, do CTN, c.c. arts. 19 a 21 da LM 11.154/91, que atribui aos tabeliães, escrivães, notários, oficiais de Registro de Imóveis e demais serventuários, a responsabilidade solidária pelo cumprimento da obrigação tributária principal devida sobre os atos por eles praticados em razão de seu ofício.

\subsection{Aspecto quantitativo da hipótese de incidência}

Dois itens compõem o aspecto quantitativo da hipótese de incidência do ITBI: a sua base de cálculo e a alíquota. Em ambos há assuntos de interesse a serem abordados, que é o que se fará nos itens subseqüentes.

\subsubsection{Base de cálculo}

A base de cálculo do ITBI é o valor venal dos bens ou direitos transmitidos. (CTN, art. 38 e LM 11.154/91, art. $7^{\circ}$ ).

Embora até possa parecer desnecessário, cabe ressaltar que, em caso de cessão de direitos relativos à aquisição de imóveis, a base de cálculo referese ao valor venal dos direitos cedidos, e não do imóvel envolvido na transação (a própria legislação municipal paulistana explicita: "nas cessões de direitos à aquisição, o valor ainda não pago pelo cedente será deduzido da base de cálculo" - LM 11.154/91, art. $7^{\circ}$ ).

Resta definir precisamente o que vem a ser valor venal, e, conseqüentemente, qual é exatamente quantum a ser utilizado para fins de cálculo do ITBI.

A interpretação literal do dispositivo leva à conclusão de que o valor venal é o valor de mercado do bem. Valor venal é "o valor de venda ou 
seja o valor de mercado" (Tenório e Maia, Dicionário..., p. 276). Para Eduardo Jardim, "o aludido parâmetro supõe que a coisa seja vendida pelo preço de mercado, vale dizer, aquele que o bem pode obter em condiçôes normais de mercado" (Dicionário..., p. 162). No mesmo sentido De Plácido e Silva: "é o valor de venda, ou o valor mercantil, isto é, o preço por que as coisas foram, são ou possam ser vendidas".

Veja-se, pois, que, pelo exposto, nenhuma dúvida pode haver no sentido de que a base de cálculo do ITBI é o valor de mercado do imóvel, ou seja, o valor pelo qual é vendido, à vista, em condiçôes normais de negociação. Neste sentido cabe destacar a manifestação precisa do $1^{\circ}$ Tribunal de Alçada Civil de São Paulo, segundo o qual "Valor venal é, em síntese, valor de mercado à vista" (Ap. 723.166-5 - 11을. Ext. - j. 17.4.97, rel. Juiz Silveira Paulilo), bem como de Aires Barreto: "Valor venal é o preço provável que o imóvel alcançará para compra e venda à vista, diante de mercado estável e quando o comprador e vendedor têm plena consciência do potencial de uso e ocupação que ao imóvel pode ser dado" (Imposto..., p. 341).

Importante consequêencia desta assertiva é a conclusão de que a base de cálculo do imóvel não corresponde necessariamente ao valor pelo qual se efetuou a transação. Tanto assim é que a própria legislação do munićpio de São Paulo prevê que "em nenhuma hipótese, o imposto será calculado sobre valor inferior ao valor do bem, utilizado, no exercício, para base de cálculo do Imposto sobre a Propriedade Predial e Territorial Urbana, atualizado monetariamente de acordo com a variação dos índices oficiais, no período compreendido entre $1^{\circ}$ de janeiro e a data da ocorrência do ato" (art. $8^{\circ}$ ). Desta forma, caso se tenha efetivado uma transação imobiliária por valor inferior àquele estabelecido pela Municipalidade para o cálculo do IPTU, devidamente atualizado, este último prevalecerá.

Ora, em assim sendo, é também lógico concluir que não se pode considerar como base de cálculo um valor superior ao valor de mercado do bem, ainda que a negociação tenha ocorrido por este valor. É o que pode ocorrer, por exemplo, se houver a inclusão, na base de cálculo do ITBI, na hipótese de venda do imóvel, de eventuais valores referentes e juros e outros acréscimos que incidam, ou incidiram, no caso de ter sido o imóvel financiado, e que, em sendo somados, farão o valor da transação chegar a um número muitas vezes bastante superior àquele estabelecido para o caso de venda à vista, a preços de mercado, em condições normais. Nesta hipótese, mais razoável é admitir que, na falta de outros elementos, utilize-se como base de cálculo do 
ITBI o mesmo valor previsto pela Municipalidade para o imóvel para fins de tributação pelo IPTU, devidamente atualizado.

Importante ressaltar ainda que o valor do imóvel deve ser aquele ao tempo da alienação, e não da promessa (súmula 108 do STF).

\subsubsection{A alíquota do ITBI e a questão da progressividade}

A questão da fixação das alíquotas do ITBI passou a ter um grande interesse acadêmico a partir da discussão acerca da possibilidade ou não de que sejam fixadas de forma progressiva, com valores maiores à medida em que aumenta a base de cálculo do imposto.

No município de São Paulo, a legislação prevê alíquotas progressivas, variando de 2 a $6 \%$, crescentes conforme o valor venal do imóvel (LM 11.154/91, art. 10 ).

Muitas foram as ações questionando este forma de tributação, o que deu origem a farta manifestação da jurisprudência acerca do tema, bem como da doutrina.

O centro da controvérsia cinge-se à constitucionalidade ou não da fixação de alíquotas progressivas, crescentes conforme o aumento da base de cálculo.

Sustentam os defensores da tese da inconstitucionalidade desta forma de tributação, em síntese, o argumento de que a Constituição não prevê esta possibilidade. Neste sentido já se manifestou inclusive o $1^{\circ}$ Tribunal de Alçada Civil de São Paulo, sumulando a tese: "É inconstitucional o art. 10 da Lei 11.154, de 30.12.91, do Município de São Paulo, que instituiu alíquotas progressivas para o Imposto de Transmissão de Bens Imóveis" (súmula 45). Em um de seus acórdãos, explicita a argumentação: "A Constituição Federal, no parágrafo segundo do aludido art. 156, disciplinou vários aspectos do imposto de transmissão, sem qualquer referência à progressividade. Assim, a intexpretação sistemática da seção $\mathrm{V}$, que é específica aos impostos dos Municípios, leva à conclusão de que o constituinte não pretendeu estender a progressividade ao imposto de transmissão inter vivos" (Ac. un, da 90 C. do $1^{\circ}$ TAC SP - Ap. 547.879-5 - j. 19.9.95, in RT 726/273). A questão já foi inclusive objeto de apreciação pelo STF, que decidiu pela inconstitucionalidade das aliquotas progressivas do ITBI (Ac un do STF-Pleno declarando a inconstitucionalidade do art. 10, II, da Lei n. 11.154, de 30.12.1991, do Município de São Paulo/SP - RE 234.105-3-SP - rel. Min. Carlos Velloso - j. 8.4.99) 
Já os partidários da tese adversa concentram seus argumentos na desnecessidade desta previsão, por serem as alíquotas progressivas formas de tributação que seguem o princípio da capacidade contributiva, consagrado no art. 145 , parágrafo $1^{\circ}$, da Constituição.

Ousando discordar da decisão do Supremo Tribunal Federal, entendo ser esta úlima a tese que melhor se ajusta à hipótese.

A progressividade de alíquotas é técnica tributária consagrada e aplicada a vários impostos, tendo inclusive o texto constitucional determinado expressamente sua observância no imposto de renda (art. $153, \S 2^{\circ}$, l). E a maior parte dos estudiosos vê esta técnica como correta no sentido de realizar a Justiça Fiscal, sendo ela inerente ao princípio da capacidade contributiva.

No ordenamento jurídico italiano, a progressividade é vista como princípio inerente e integrante da capacidade contributiva. E o que se depreende das palavras do jurista italiano Maffezoni: "Si puo dire in conclusione che il principio di capacità contributiva e di progressività costituiscono, nel nostro ordinamento, una sintesi inscindible, essendo l'uno il modo di essere dell'altro" (Il principio..., p. 299).

A doutrina pátria também é rica em defensores da tributação progressiva.

Para Misabel Derzi, "a graduação dos impostos, de forma que os economicamente mais fortes paguem progressivamente mais por esses gastos do que os mais fracos, levará a uma maior justiça social" (Princípio..., p. 178).

Geraldo Ataliba defende a progressividade como "uma excelente maneira de realizar o princípio da capacidade contributiva informador dos impostos". Evai além, ao afirmar que "como todos os impostos sem nenhuma exceção, necessariamente são baseados no princípio da capacidade contributiva, todos são passíveis de tratamento progressivo" (Progressividade..., p. 49).

Não obstante a progressividade atinja resultados mais precisos quando é aplicada sobre a renda auferida, é de se admitir que a progressividade do ITBI obedece ao princípio da capacidade contributiva. É legítima a presunção de que o adquirente de um imóvel de maior valor tem maior capacidade de arcar com o ônus tributário do que quem negociou um imóvel de valor menos elevado, devendo por isto suportar uma tributação mais gravosa.

Ademais, não obstante afirmem neste sentido alguns dos defensores da proporcionalidade como critério de justa tributação, a progressividade não significa necessariamente uma penalização dos mais ricos.

Primeiramente porque, entendendo-se a progressividade como sendo, por si só, ilegítima, sem levar-se em consideração outros fatores, como o limite 
máximo das alíquotas, basta o legislador tributar todos os contribuintes pela aliquota máxima que nada se poderá questionar em termos de progressividade.

Em segundo lugar, porque a progressividade é maneira de assegurar a justa tributação dos indivíduos, estabelecendo entre eles uma igualdade de sacrificios, critério já consagrado pelos estudiosos do assunto como o mais adequado em termos de Justiça Fiscal.

As palavras do já citado Paul Hugon são esclarecedoras a respeito da matéria, e consagram a progressividade como instrumento de Justiça Fiscal: "A fixação do imposto deve atender à capacidade contributiva de cada um. Em outros termos, o princípio da justiça fiscal indica que o imposto deve ser pago em uma medida que assegure um sacrificio igual para cada contribuinte. Que entenderemos por isso?

Em primeiro lugar, o imposto pode ser medido proporcionalmente aos recursos do contribuinte. Assim concebido, ele levanta sempre a mesma parte da materia taxada, seja qual for a sua importancia. Por exemplo, o imposto será de $10 \%$ do rendimento da propriedade territorial, seja ele 1.000 ou 1 milhão. O montante do imposto varia, pois, como o próprio rendimento.

Esta forma de imposição corresponde exatamente ao conceito que assimila o imposto a uma troca de serviços entre o Estado e os cidadãos: cada contribuinte paga proporcionalmente ao que ele possui da riqueza nacional.

Este cálculo do imposto, é simples e objetivo. Simples, porque determina uma igualdade de quotas-partes a serem pagas. Objetivo, porque elimina qualquer arbitrariedade de apreciação pessoal dos recursos dos contribuintes.

Mas, como já demonstramos, a capacidade contributiva cresce mais do que proporcionalmente aos recursos de cada um. A utilidade-final de cada uma das unidades que compõe uma renda de 1.000 cruzeiros, por exemplo, é maior do que a de cada uma das unidades de uma renda de 1 milhão de cruzeiros. O sacrificio individual que consiste em consagrar ao imposto $10 \%$ de uma renda de 1.000 , é superior àquele que consiste em consagrar ao imposto $10 \%$ de uma renda de 1 milhão. No primeiro caso, o imposto poderá ser pago em detrimento do necessário à existência: no segundo caso, ele será pago simplesmente sobre o supérfluo.

O imposto proporcional não é, pois, um cálculo verdadeiro da capacidade contributiva, uma vez que não permite assegurar a igualdade de sacrificio. É pela progressividade do imposto que vamos procurar obter maios exatidão neste cálculo: é pela progressividade que tendemos a satisfazer a justiç fiscal no imposto. 
Com a progressividade, a taxa do imposto se eleva à medida que a importância da matéria tributável aumenta. $O$ imposto progressivo permite levantar sobre os recursos taxados, uma parte tanto maior quanto mais importante for o valor destes recursos. Em outras palavras, o montante do imposto aumenta mais que proporcionalmente aos recursos tributáveis. Se o rendimento de 1.000 cruzeiros é gravado com um imposto de $2 \%$, o de 1 milhão será gravado, por exemplo, com um imposto de $6 \%$.

O fundamento da progressividade é o de igualar o sacrificio fiscal de todos os contribuintes: repousa na observação lembrada acima, e que é a base de cálculo moderna da utilidade, a saber, que o valor de um bem diminui à medida que a quantidade deste bem aumenta, uma vez que cada nova unidade do bem permite satisfazer necessidades cada vez menores...

...Na verdade, atualmente, o princípio sobre o qual repousa o imposto progressivo, não é mais seriamente atacado: as objeções se referem principalmente a certas dificuldades de sua aplicação e a certos abusos a que dão lugar.

A aplicação da progressividade é suscetível realmente, de modalidades atenuadas e modalidades acentuadas. É a propósito desta última que o imposto progressivo é freqüentemente criticado"

Ante o exposto, há que se reconhecer a progressividade como instrumento eficiente e inerente ao princípio da capacidade contributiva. E, como já escrevi anteriormente, "a tributação progressiva é a forma de tributação que melhor obedece ao princípio da capacidade contributiva, pois visa igualar o sacrificio dos contribuintes e obter, assim, a eqüidade vertical" (Princípios..., p. 98).

Portanto, sendo a capacidade contributiva um dos princípios tributários consagrados expressamente em nosso ordenamento jurídico, em face do disposto no art. $145, \S 1^{\circ}$, da Constituição, correta é a utilização de alíquotas progressivas, crescentes conforme o valor venal do imóvel.

\section{Conclusão}

De todo o exposto, algumas conclusões podem extraídas:

4.1. O ITBI incide sobre o valor que exceder ao respectivo quinhăo na partilha de bens imóveis entre cônjuges, em razão de separação judicial, desde que este excesso se dê a título oneroso, e não gratuito.

4.2. O ITBI não incide sobre a aquisição de imóvel por usucapião.

4.3. Relativamente ao aspecto temporal da hipótese de incidência, o ITBI incide por ocasião da lavratura da escritura definitiva de compra e venda do imóvel.

4.4. A base de cálculo do ITBI corresponde ao valor de mercado do imóvel, para pagamento à vista, em condições normais de negociação. 
4.5. É constitucional a utilização de alíquotas progressivas do ITBI, crescentes conforme o valor do imóvel.

\section{BIBLIOGRAFIA}

ATALIBA, Geraldo. Hipótese de incidência tributária. São Paulo: Revista dos Tribunais, 1990.

ATALIBA, Geraldo. Progressividade e capacidade contributiva. In "V Congresso Brasileiro de Direito Tributário". Separata da Revista de Direito Tributário. São Paulo: Revista dos Tribunais, 1991.

BARRETO, Aires F. Imposto sobre a transmissão de bens imóveis - ITBI. In MARTINS, Ives (org.). "Curso de Direito Tributário". Belém: CEJUP - CEEU, 1993, vol. II, pp. 331/344.

BARRETO, Aires. Progressividade dos impostos e o ITBI. In Repertório IOB de Jurisprudência $1 / 10246$.

CARVALHO, Paulo B. Curso de Direito Tributário. São Paulo: Saraiva, 1993. COLOMA. Teófilo D. Imposto de transmissão de bens imóveis inter vivos na Constituição Federal de 1988 e na lei complementar. São Paulo, USP (dissertação de mestrado), 1990.

CONTT, José Mauricio. Sistema Constitucional Tributário interpretado pelos Tribunais. São Paulo: Oliveira Mendes, 1997.

CONTI, José Mauricio. Princípios tributários da capacidade contributiva e da progressividade. São Paulo: Dialética, 1996.

DERZI, Misabel A. M. Principio da Igualdade no Direito Tributário e suas manifestações. In "V Congresso Brasileiro de Direito Tributário". Separata da Revista de Direito Tributário. São Paulo: Revista dos Tribunais, 1991.

FANUCCHI, Fábio. Curso de Direito Tributário Brasileiro. São Paulo: IBET - Resenha Tributária, 1986.

HARADA, Kiyoshi. ITBI progressivo. In Repertório IOB de Jurisprudência 1/10245. HUGON, Paul. O imposto. Teoria moderna e principais sistemas. São Paulo: Renascença, 1945.

IARDIM, Eduardo M. F. Dicionário de Direito Tributário. São Paulo: Saraiva, 1995. MACHADO, Hugo B. Curso de Direito Tributário. São Paulo: Malheiros, 1996. MAFFEZONI, F. II principio di capacità contributiva nell'ordinamento costituzionale italiano. Torino: Giappichelli, 1965.

SAMPAIO, Alcides F. ITBI: momento de incidencia na compra e venda de imóveis. In Revista Dialética de Direito Tributário n ${ }^{\circ} 25, \mathrm{pp} .14 / 36$.

SENADO FEDERAL. Constituições do Brasil. Brasília: Subsecretaria de edições técnicas do Senado Federal, 1986.

SILVA, De Plácido. Vocabulário Jurídico. Rio de Janeiro: Forense, 1986.

SILVA, Edgard Neves. Aspecto temporal do fato gerador do ITBI - aspectos tributário e civil do tema. In Revista Dialética de Direito Tributário n ${ }^{\circ} 12$, pp. 98/100. TENÓRIO, Igor e MAIA, José M. Dicionário de Direito Tributário. Rio de Janeiro: Forense, 1996. 